UDK: 624.012.4.059

DOI: https://doi.org/10.24867/14CG07Andjelic

\title{
PROCENA STANJA I ENERGETSKA SANACIJA VIŠESPRATNE STAMBENE ZGRADE KOJA JE IZGRAĐENA PRIMENOM IMS TEHNOLOGIJE
}

\section{ASSESSMENT AND ENERGY REHABILITATION OF A MULTI-STORY RESIDENTIAL BUILDING THAT WAS BUILT BY IMS TECHNOLOGY}

\author{
Jelena Anđelić, Fakultet tehničkih nauka, Novi Sad
}

\begin{abstract}
Oblast - Građevinarstvo
Kratak sadržaj - Rad se sastoji iz dva dijela, teorijskoistraživačkog $i$ praktičnog. U teorijsko-istraživačkom dijelu je obrađen montažni sistem gradnje sa posebnim osvrtom na industrijski montažni sistem IMS. U praktičnom dijelu urađena je procena stanja višespratne stambene zgrade $u$ Novom Sadu. Zatim je uraden proračun energetske efikasnosti za postojeće stanje objekta. Nakon predloženih mjera enegetske sanacije ponovo je urađen proračun energetske efikasnosti zgrade. Na kraju, upoređeni su rezultati ova dva proračuna.
\end{abstract}

Ključne reči: Montažna gradnja, IMS, Energetska efikasnost, Sanacija, Knauf insulation

Abstract - The paper consists of two parts, theoreticalresearch and practical. In the theoretical research part, the prefabricated construction system is analyzed with a special reference to the industrial prefabricated system IMS. In the practical part, an assessment of the condition of a multi-store residential building in Novi Sad was done. Then, an energy efficiency calculation was carried out for existing condition of building. After the proposed energy rehabilitation measures, the calculation of the energy efficiency of the building was done again. Finally, the results of these two calculations were compared.

Keywords: Prefabricated construction system,Energy efficiency, Rehabilitation, Knauf Insulation

\section{UVOD}

\subsection{Montažna gradnja}

Tendencija u savremenom građevinarstvu je masovna izgradnja objekata različitih namjena. Ostvarivanje ove tendencije moguće je samo na principima industirjskog načina proizvodnje, što uslovljava industrijalizaciju i prefabrikaciju u građevinarstvu.

Montažna gradnja podrazumijeva proizvodnju dijelova odnosno prefabrikata u povoljnim (fabričkim) kontrolisanim uslovima proizvodnje ili proizvodnje na gradilištu u slučaju teških elemenata i njihovo spajanje na gradilištu (Slika 1.)

Montažni sistem predstavlja skup montažnih elemenata koji se međusobnim povezivanjem pretvara u konstruktivnu cijelinu i može biti otvoren i zatvoren.

\section{NAPOMENA:}

Ovaj rad proistekao je iz master rada čiji mentor je bila dr Mirjana Malešev, red. prof.
Pod otvorenim montažnim sistemom podrazumijevaju se elementi univerzalnog karaktera (modularna i tipska ograničenja), a pod zatvorenim se podrazumijevaju elementi upotrebljivi samo za određenu proizvodnju. Poređenjem brzine montažne i in-situ (monolitne) gradnje, dolazi se do zaključka: In-situ gradnja zahtijeva manju količinu vangradilišnog rada, što praktčno rezultira linearnom brzinom gradnje.

Motažna gradnja zahtijeva veliku količinu vangradilišnog rada prije početka izgradnje objekta ali postiže veliku brzinu gradnje nakon završetka pripremnih radova $\mathrm{i}$ obezbijeđuje manju količinu završnih radova.

Prednosti industrijskog načina gradnje su: smanjenje količine fizičkog rada, brža gradnja objekta, produženje građevinske sezone na skoro cijelu godinu, ušteda drvene građe za oplatu, postizanje boljeg i ravnomjernijeg kvaliteta elemenata i konstrukcije, povećanje sigurnosti i trajnosti objekta i niza drugih.

S druge strane, ovakav način građenja zahtijeva veće početne investicije (oprema za prefabrikaciju), kvalifikovanu radnu snagu, skupu i sofisticiranu mehanizaciju, skup transport elemenata i problemi transporta, problemi montaže, monolitizacije i popustljivosti veza.

Montažna gradnja može naći primjenu kod elemenata teških nekoliko kilograma do elemenata teških više tona, objekata niskogradnje, visokogradnje i hidrogradnje. Mogu se koristiti kao konstruktivni, nekonstruktivni, ukrasni elementi, itd. [1] [8].

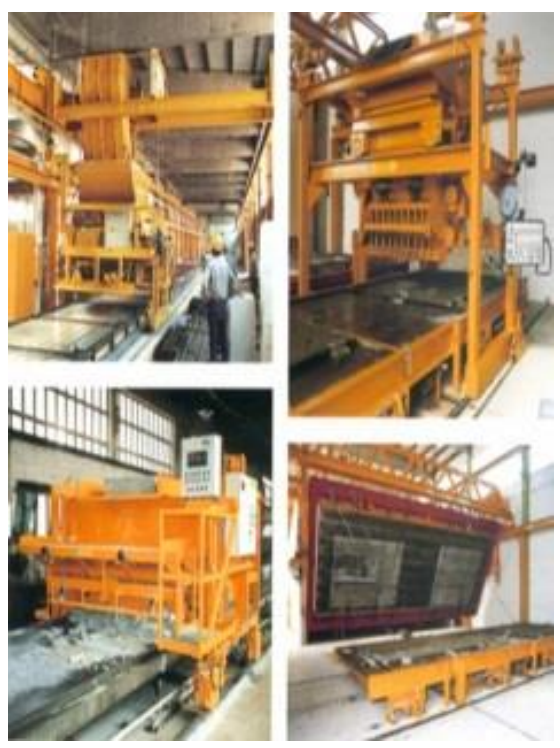

Slika 1. Pogon i oprema za prefabrikaciju [8] 


\subsection{Industrijski montažni sistem - IMS}

Jedan od najčešće korišćenih montažnih sistema kod nas kada je u pitanju stambena izgradnja i gradnja poslovnih objekata je IMS sistem od prednapregnutog betona. IMS sistem je zamišljen i ostvaren u Instititutu za ispitivanje materijala u Beogradu 1956. godine. Osnovna ideja IMS sistema jeste u konstrukciji minimalnog broja konstruktivnih elemenata od kojih je moguće sastaviti veliki broj različitih objekata. Ova raznolikost se ogleda kako u osnovama objekata, tako i u njihovim visinama (spratnim). Težnja da se prelaskom na montažnu gradnju ne izgubi ni jedna dobra karakteristika klasično građenih armiranobetonskih konstrukcija u potpunosti je zadovoljena primjenom prednaprezanja kao načina povezivanja elemenata u monolitnu cjelinu. Ovako koncipiran montažni sistem omogućio je vrlo široku primjenu počev od stambenih zgrada, škola, bolnica, hotela, poslovnih objekata, do industrijskih objekata, magacina i dr. [1].

Konstrukciju sistema IMS čine montažne ćelije kvadratnog ili pravougaonog oblika, dimenzija od 3,0 $\mathrm{m} \times 3,0$ $\mathrm{m}$ do $7,2 \mathrm{~m} \times 7,2 \mathrm{~m}$. Ćeliju formiraju četri stuba i jedna kasetirana tavanična ploča između njih (Slika 2.). Ovo su ujedno i osnovni elementi koji prihvataju vertikalno opterećenje. Povezivanje stubova i tavanica u monolitnu cjelinu postiže se kablovima za prednaprezanje. Prihvatanje horizontalnih sila vjetra i seizmičkih potresa povjereno je prvenstveno betonskim platnima za ukrućenje, a dijelom i skeletu konstrukcije.
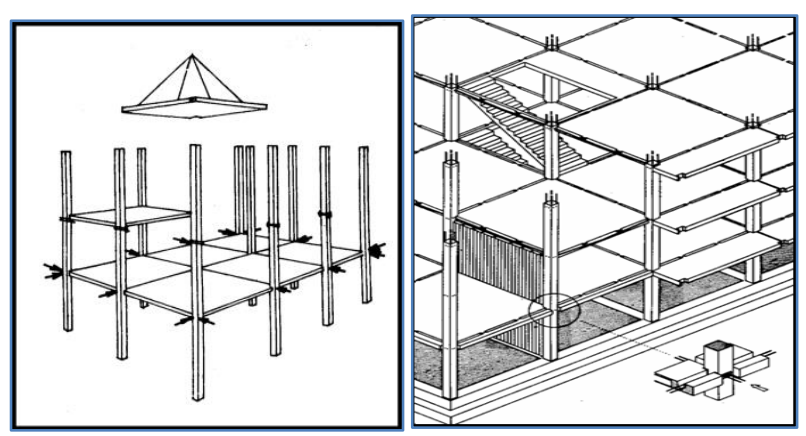

Slika 2. Koncept konstrukcije IMS sistema [1]

Osim ovih nosećih elemenata, postoje i drugi elementi čija je uloga da upotpune konstrukciju i omoguće njeno normalno korišćenje. Kompletna konstrukcija IMS sistema sastoji se od sledećih elemenata: primarni elementi noseći dijelovi konstrukcije (stubovi, tavanične ploče, armiranobetonska platna za ukrućenje, stepeništa, ivični nosači); sekundarni elementi - nenoseći dijelovi konstrukcije (fasadni elementi, pregradni zidovi, sanitarni blokovi, kuhinjske kabine); tercijarni elementi (obloge, stolarija i sl.).

Primjenjuju se gotovo svi načini fundiranja koji se inače koriste kod višespratnih zgrada (temelji samci, temeljenje na pločama, na temeljnim roštiljima, kao i na šipovima). Dobra osobina IMS konstrukcije je što nije jako osjetljiva na nejednaka slijeganja oslonaca, ali u slučaju izraženog slijeganja ovu činjenicu proračunom ne treba zanemariti.

Montaža elemenata montažno skeletne konstrukcije izvodi se kranovima ili pokretnim dizalicama kod nižih objekata (Slika 3.). Redoslijed montaže je sledeći: prije montaže stubova mora se sprovesti kontrola položaja ankernih rupa u temeljima, odnosno položaj ispuštenih ankera iz temelja; potom se montiraju stubovi; nakon što su montirani stubovi mogu se montirati tavanice; zidovi za ukrućenje se montiraju nakon montaže i utezanja donjeg nivoa tavanica, a prije montaže gornjeg nivoa.

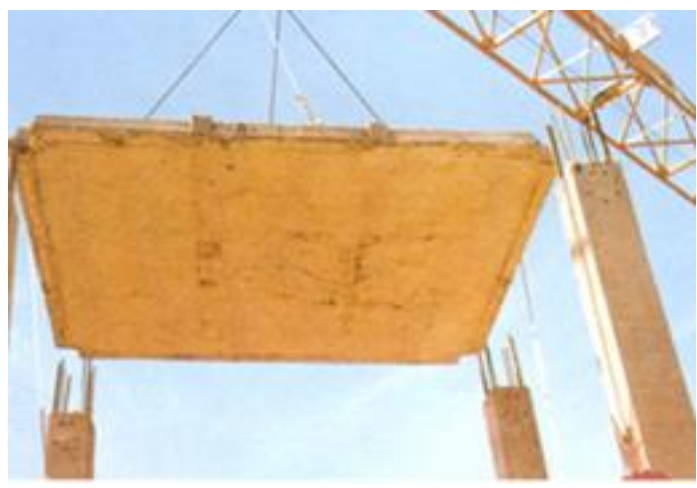

Slika 3. Montaža elemenata IMS sistema [8]

\section{PROCENA STANJA OBJEKTA}

\subsection{Tehnički opis}

Objekat se nalazi u Novom Sadu na adresi Partizanskih brigada br.4. Objekat pripada I etapi stambenog bloka na Novom Naselju koja je građena 1977. godine.

Objekat je približno kvadratne osnove dimenzija 21,70 m x $17,50 \mathrm{~m}$ i spratnosti P+8+potkrovlje. Ulaz u objekat je sa dvije strane. Jedan ulaz sa prilaznom rampom i četri stepenika se nalazi na zapadnoj a drugi ulaz na istočnoj strani (Slika 4.).

Prizemlje se sastoji iz ulaznog vjetrobrana, prostorije za odlaganje bicikala, deponije smeća i društvenih prostorija (lokali, servisi, zanatske radionice, manji kulturni i ugostiteljski punktovi). Javne i zajedničke prostorije prizemlja imaju čistu (korisnu) visinu od $3,0 \mathrm{~m}$. Vertikalna komunikacija se sprovodi pomoću jednokrakog stepeništa i dva lifta. Jedan lift je nosivosti $300 \mathrm{~kg}$ namijenjen za 4 osobe, a drugi je nosivosti $450 \mathrm{~kg}$ i namijenjen je za 6 osoba. Sadržaj i strukturu tipskih spratova čine: trosoban stan, dvosoban i jednosoban stan.

Svaka tipska etaža broji po dva tipska stana, što je ukupno 48 stanova $\mathrm{P}=2820,80 \mathrm{~m}^{2}$. Strukturu potkrovlja čine garsonjera i dva različitih dimenzija jednosobna stana. Potkrovlje broji po dva tipska stana svake vrste, odnosno 6 stanova $\mathrm{P}=214,12 \mathrm{~m}^{2}$.

Konstruktivni sistem zgrade je skeletna konstrukcija sastavljena od montažnih stubova i tavaničnih ploča. Spajanje ova dva elementa u skeletnu konstrukciju izvršeno je prednaprezanjem. Konstrukcijski raster stubova je 4,20 m x 4,20 m. AB montažni stubovi su izvedeni kao dvoetažni i troetažni, presjeka $34 \mathrm{~cm} \mathrm{x} 34 \mathrm{~cm}$. IMS međuspratna tavanica je izvedena kao kasetirana tavanica sa ortogonalnim sistemom sekundarnih nosača (tavanica sa gornjom betonskom pločom i rebrima). Ivični nosači su rađeni kao primarni i kasnje su utegnuti kablovima za prednaprezanje. Debljina IMS međuspratne tavanice je 22 $\mathrm{cm}$ (betonska ploča $4 \mathrm{~cm}+$ rebro $18 \mathrm{~cm}$ ). Konzolne tavanice su raspona $1,50 \mathrm{~m}$ i za datu osnovu objekta su zastupljene u maksimalnom broju dvadeset normalnih + četrnaest konzolnih tavanica. 


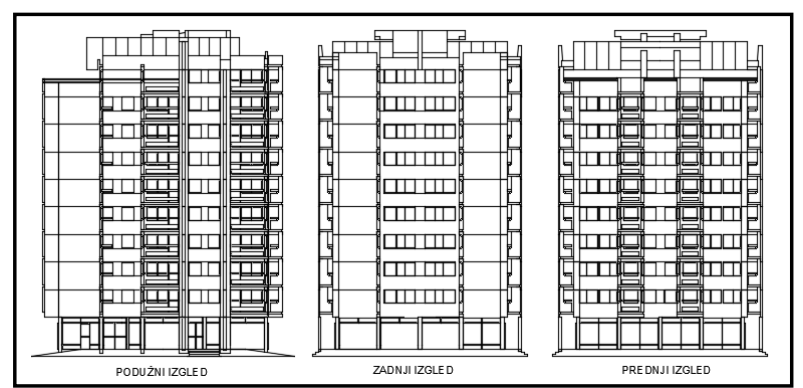

Slika 4. Izgledi višespratne stambene zgrade

Fundiranje zgrade je izvršeno na $A B$ ploči $\mathrm{d}=40 \mathrm{~cm}$, koja je ojačana unakrsnim $A B$ gredama 100/50 cm.

\subsection{Vizuelni pregled objekta i analiza uočenih oštećenja}

Kako je objekat u funkciji (u trenutku vizuelnog pregleda), bilo je moguće pristupiti samo pojedinim dijelovima objekta. Provjerene su dimeznije dostupnih elemenata i konstrukcije i njihova usklađenost sa projektom predviđenim dimezijama (stubovi u prizemlju, stubovi na ulazu u objekat, stepenište kao i pojedini zidni paneli i stubovi koji se nalaze u hodnicima svih etaža). Vizuelnim pregledom se provjeravaju dimenzije konstruktivnih elemenata i geometrija objekta. Registruju se i klasifikuju vidljivi defekti i oštećenja, a potom se vrši njihova sistematizacija i određuje uzrok njihovog nastanka, odnosno formira se zaključak o stanju konstrukcije [7].

\subsubsection{Glavna fasada objekta - spoljašnjost objekta}

Pregledom prilaznih elemenata objekta i uporedbom izvedenog stanja i stanja datog u dostupnoj projektnotehničkoj dokumentaciji uočena je razlika kod pristupnih rampi. Na izvedenom stanju date rampe se ne pružaju cijelom dužinom fasade, nego se završavaju sa stepeništem. Na prilaznom stepeništu uočeni su tragovi odlamanja i otpadanja obloge, dok na prilaznim rampama uočena su oštećenja u obliku ispucalog betona usljed dugotrajne izloženosti dejstva mraza, zatim mehanička oštećenja i biološka korozija.

$\mathrm{Na}$ zidnim panelima prizemlja obloženim fasadnom opekom uočena su mjestimična ljuskanja dekorativnog premaza fasadne opeke, kao i mehanička oštećenja u vidu odlamanja dijelova opeke. $\mathrm{Na}$ prefabrikovanim dekorativnim betonskim panelima prizmlja vizuelnim pregledom su uočeni defekti i oštećenja koji kako narušavaju trajnost tako i estetiku samih elemenata. Na zidnim panelima viših spratova uočene su mrlje kako od klima uređaja koje ispuštaju vodu i vlaže zidne panele tako i od atmosferalija koje se slivaju sa ravnog krova na panele i ispiraju dekorativnu boju sa betonskih panela. Karakteristična je pojava biološke korozije na vrhovima panela poslijednjeg sprata kao i sprata niže. Uočena je pojava horizontalnih, dijagonalnih prslina i pukotina kao i mreža ortogonalnih prislina na većini zidnih panela nezavisno od spratnosti. Pojava spomenutih prslina i pukotna je posljedica prefabrikacije usljed termičke obrade (zaparivanja elemenata u cilju ubrzanog očvršćavanja) elemenata. Pored spomenutih mrlja od vlage koje se smanjuju sa etažama, uočene su mrlje koje su posljedica difuzije vodne pare i koje su vidljive skoro na svim etažama.
Na ivičnim balkonskim prefabrikovanim panelima uočena je korozija armature, koja je posljedica defekta - nedovoljne debljine zaštitnog sloja betona i naizmjeničnog vlaženja površine elemenata sa obe strane.

\subsubsection{Unutrašnjost objekta}

Pregledom unutrašnjosti objekta (prostorije kojima je bio omogućen pristup) izvšeno je poređenje izvedenog stanja sa stanjem datim u dostupnoj projektno-tehničkoj dokumentaciji. Nisu uočene nikakve razlike tj. izvedeno stanje se poklapa sa projektovnim. U predulaznom prostoru vizuelnim pregledom uočena su mehanička oštećenja u blizini ulaznih vrata pojava prslina i pukotina na spoju zida sa spuštenim plafonom.

Pregledom hodnika u prizemlju uočeno je ljuskanje obloge zida i plafona na mjestu pojave vlage koja je uslijedila nakon pucanja instalacija u kupatilu stana koji se nalazi neposredno iznad. Na stepenišnom kraku sa donje strane uočena je rupičasta površina u vidu ljuskanja dekorativnog premaza. Na azbestnim pločama uočena su i mehanička oštećenja nastala usljed čestog otvaranja i zatvaranja istih u svrhu popravljanja instalacija koje se nalaze iza njih. Pregledom potkrovlja uočeno je otpadanje zaštitnog sloja maltera i otkrivanje zida od opeke. Zidovi potkrovlja su izloženi vlaženju usljed slivanja vode sa krova, iz tog razloga je došlo do bubrenja zaštitnog sloja maltera i njegovo naknadno otpadanje [7].

\subsection{Zaključak o stanju objekta}

Analizom registrovanih oštećenja, može se zaključiti da ni jedno od oštećenja ne možemo smatrati glavnim. Svaki od navedenih uzroka oštećenja je uglavnom u sprezi sa drugim uzrocima koji zajedno dovode do spomenutih oštećenja. S obzirom da je zgrada izgrađena 1977. godine i da ulazi u svoju 44.-u godinu postojanja, bez informacija o sanacijama u bliskoj prošlosti zaključuje se da je trajnost objekta smanjena, dok stabilnost i nosivost nisu narušene. Funkcijonalnost zavisi od stepena održavanja objekata. S obzirom da je u pitanju primarno stambeni objekat sa poslovnim prostorom u prizemlju, stepen funkcionalnosti je zadovoljavajući.

\section{ENERGETSKA EFIKASNOST - POSTOJEĆE STANJE}

Proračun je u svemu sproveden prema važećem Pravilniku o energetskoj efikasnosti zgrada „Službeni glasnik RS“ br. 061/2011 [2]. Elementi konstrukcije su najpre podjeljeni na transparentne i netransparentne u zavisnosti od slojeva i položaja ovih elemenata. Definisano je 14 netransparentnih i 13 transparentnih pozicija. Za svaku od pozicija urađen je proračun građevisnke fizike koji podrazumjeva određivanje koeficijenata prolaza toplote, a za netransparentne sklopove određeni su: raspored temperatura, minimalna otpornost sklopa, difuzija vodene pare i parametri letnje stabilnosti. Svi analizirani sklopovi su imali veći koeficijent prolaza toplote od pravilnikom propisane vrednosti. Nakon izvršenog proračuna za svaku poziciju , pristupilo se proračunu toplotnih gubitaka i dobitaka zgrade kao cjeline, u cilju određivanja potrebne energije za obezbeđenje osnovnih uslova komfora. Proračunati gubici toplote prikazani su na Slici 5. 


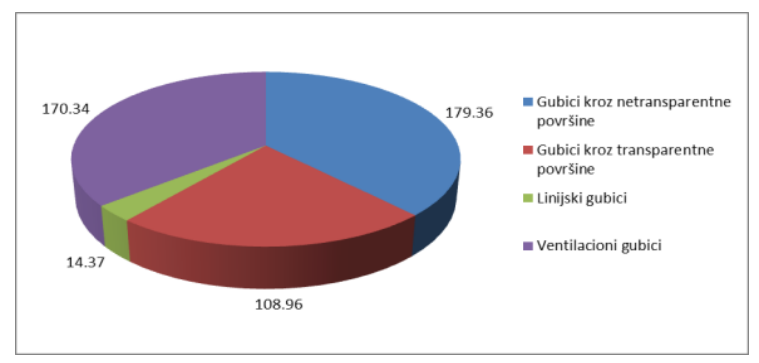

Slika 5. Gubici toplote, postojeće stanje

$\mathrm{Na}$ kraju, proračunata je ukupna potrebna energija za grijanje zgrade na godišnjem nivou, na osnovu kojeg je zgrada svrstana u energetski razred $\mathrm{G}$.

\section{ENERGETSKA SANACIJA I ENERGETSKI RAZRED SANIRANOG OBJEKTA}

Pored toga što nijedan od elemenata nije zadovoljio propisane vrednosti koeficijenta prolaza toplote, utvrđeno je i da veliki broj elemenata ima malu termičku masu, pa je izborom termoizolacije povećana i termička masa problematičnih elemenata. Potrebne debljine termoizolacionih materijala poračunate su iz uslova da najkritičniji sklop ispuni uslov za najveći dozvoljeni koeficijent prolaza toplote.

Za termoizolaciju spoljašnjih zidova izabrana je kamena vuna debljine $8 \mathrm{~cm}$, koja je u sklopu ETICS sistema fasade. Za termoizolaciju unutrašnjeg zida izabrana je Multipor ploča debljine $7,5 \mathrm{~cm}$, proizvođača YTONG.

Kao novo rešenje za zamenu dotrajalih slojeva ravnog krova, usvojen je neprohodni ravan krov proizvođača Knauf Insulation, sa termoizolacijom od kamene vune debljine $18 \mathrm{~cm}$. Za parnu branu usvojen je Knauf LDS 200 [6]. Stolarija je potpuno zamenjena dvostrukim niskoemisionim staklom 4-12-4 mm punjenim kriptonom sa 6-komornim PVC okvirima.

Ponovnim proračunom dobijeni su mnogo bolji rezultati, (Slika 6).

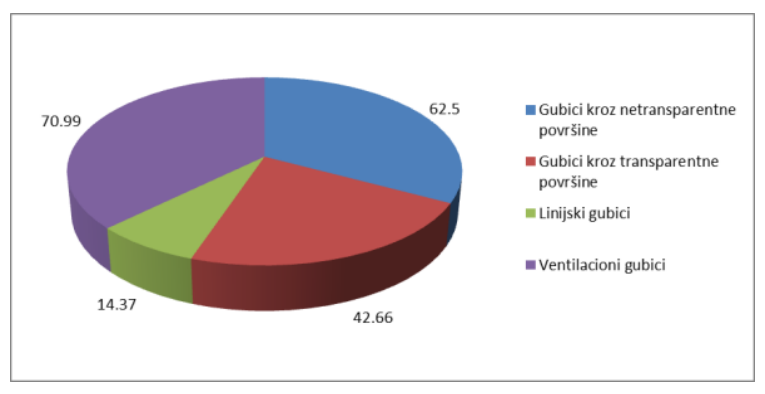

Slika 6. Gubici toplote, sanirani objekat

Daljim prorčunom utvrđeno je da objekat pripada energetskom razredu $\mathrm{C}$.

\section{ZAKLJUČAK}

$\mathrm{Na}$ osnovu rezultata vizuelnog pregleda i analizom registrovanih oštećenja i defekata utvrđeno je da su nosivost i stabilnost objekta zadovoljavajući, dok je trajnost smanjena u mjeri koja je proporcijonalna sa vijekom trajanja. Funkcijonalnost objekta u mnogome zavisi od stepena održavanja i zadovoljavajuća je.

Proračunom energetske efikasnosti utvrđeno je da objekat pripada kategoriji $\mathrm{G}$.
Kako bi se povećala trajnost i energetska efikasnost izvršena je sanacija postojećeg objekta.

Spoljašnji zidovi objekata oblažu se kamenom vunom debljine $8 \mathrm{~cm}$, koja je u sklopu ETICS sistema fasade [4].

Unutrašjni zidovi oblažu se Multipor pločama proizvođača YTONG debljine 7,5 cm [3].

Ravan krov zamjenjuje se ravnim neprohodnim krovom proizvođača Knauf Insulation. Za termoizolaciju krova usvojena je kamena vuna debljine $18 \mathrm{~cm}$ [5].

Sva stolarija je zamjenjena sa dvostrukim niskoemisionim staklom punjenim kriptonom 4-12-4 mm (Kr) sa 6komornim PVC okvirima.

Ponovljenim proračunom energetske efikasnosti objekat je svrstan u razred C. Primjenjenim mjerama poboljšan je energetski razred za četri razreda, čime se energetska sanacija smatra veoma uspiješnom (Slika 7).

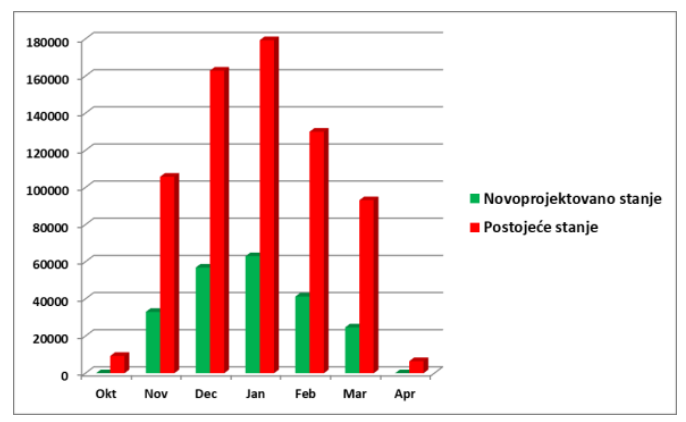

Slika 7. Potrebna energija za grijanje po mjesecima za nesanirani i sanirani objekat

\section{LITERATURA}

[1] PDFslide https://pdfslide.tips/documents/06-kratak-opis-imssistema.html?fbclid=IwAR3VFZxmm9P7gY471U8EOnfFwRejT3iNonOwLf9Xvr5VxeCBDh4lmABBMo

[2] Sl.glasnik RS" br.61/2011. Pravilnik o energetskoj efikasnosti zgrada, "Sl.glasnik RS" br.61/2011. Beograd

[3] YTONG.

https://www.ytong.rs/sta_je_ytong_multipor_1798.php

[4] Knaufinsulation. https://www.knaufinsulation.rs/kontaktnafasada

[5] Knaufinsulation. https://www.knaufinsulation.rs/ravni-krov

[6] Knaufinsulation.

https://pim.knaufinsulation.com/files/download/07_homeseal_ lds_200_aluplus.pdf

[7] Malešev M., Radonjanin V.: Trajnost i procena stanja betonskih konstrukcija, Skripta sa predavanja, Fakultet Tehničkih nauka, Novi Sad

[8] Brujić Z.: Montažne betonske konstrukcije, Skripta sa predavanja, Fakultet tehničkih nauka, Novi Sad

\section{Kratka biografija:}

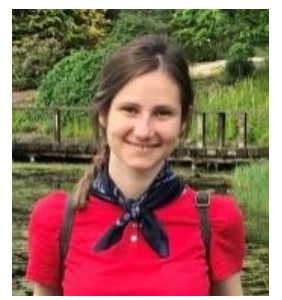

Jelena Anđelić rođen je u Prnjavoru 1996.god. Master rad na Fakultetu tehničkih nauka iz oblasti Građevinarstvo-Konstrukcije, trajnost i procena stanja i sanacija betonskih konstrukcija, odbranila je 2021.god kontakt: jelena.andjelic.gr@gmail.com 